\title{
EXPECTATIVAS DE GERENTES E ASSESSORES DE ENFERMAGEM QUANTO AO ESTILO GERENCIAL DO DIRETOR EXECUTIVO DE UM HOSPITAL DE ENSINO
}

Lúcia Marinilza Beccaria*

Neide Fávero**

BECCARIA, L.M.; FÁVERO, N. Expectativas de gerentes e assessores de enfermagem quanto ao estilo gerencial do diretor executivo de um hospital de ensino. Rev.latino-am.enfermagem, Ribeirão Preto, v. 8, n. 2, p. 83-90, abril 2000 .

Este estudo focalizou as expectativas de 13 enfermeiros de um hospital de ensino, quanto ao estilo gerencial do diretor executivo. Utilizou-se o Grid Gerencial de BLAKE \& MOUTON (1987), como referencial teórico e aplicou-se um questionário baseado no Instrumento Grid \& Liderança em enfermagem, de TREVIZAN (1993). Os resultados evidenciaram que o estilo mais esperado corresponde, no Grid Gerencial, à "gerência em equipe", ou 9.9. O segundo estilo desejado foi a "gerência do homem organizacional, "ou 5.5. Concluiu-se que, para esses enfermeiros, existem expectativas significativas relacionadas à gerência que invista em valores como confiança, respeito, comprometimento, empenho pessoal e trabalho em equipe para o alcance dos objetivos organizacionais.

UNITERMOS: gerência, liderança, enfermagem

\section{INTRODUÇÃO}

Nos últimos anos o hospital em estudo tem crescido em tamanho e complexidade, com multiplicação da demanda de serviço e das especialidades médicas, sofisticação e aperfeiçoamento de equipamentos e instalações, não acompanhados do desenvolvimento dos recursos humanos, especialmente na área de enfermagem. As transformações mencionadas têm exigido mudanças nas formas usuais de administração como mecanismo de adaptação e desenvolvimento dos recursos humanos às novas necessidades.

Apesar do grande avanço tecnológico ocorrido nesta instituição hospitalar de ensino nos últimos anos, a estrutura organizacional é tradicional, com modelo de gestão centralizada e burocrática, com alto nível de formalização e comunicação vertical, reproduzindo um conjunto de normas que determinam o comportamento da força de trabalho. Nesta forma de gestão é que se desenvolve a liderança do diretor executivo desta instituição.

Tais situações têm gerado relações de conflitos envolvendo a administração geral do hospital em foco, especialmente em relação à liderança do diretor executivo. Neste aspecto, é freqüente a queixa do gerente e assessor de enfermagem deste hospital quanto à falta de autonomia para delinear ações no âmbito da enfermagem, devido a constantes interferências do diretor executivo.

As divergências entre o serviço de enfermagem e a administração geral, composta via de regra, pela diretoria executiva, superintendência, diretoria clínica e administrativa do hospital chamaram-me a atenção desde o curso de graduação em enfermagem, quando percebia as dificuldades do gerente do serviço de enfermagem em exercer o seu papel dentro da instituição hospitalar.

Vale ressaltar que a administração geral, nesta instituição pública de grande porte, é composta pelo Conselho de Curadores, órgão normativo, deliberativo e de controle da administração; pelo Conselho Administrativo, órgão colegiado fiscalizador na área administrativa e financeira; pela Diretoria Executiva (cargo exercido por dois médicos - um titular e um vicediretor); pela Superintendência (cargo exercido por uma

\footnotetext{
* Enfermeira Auxiliar de Ensino III E do Curso de Graduação em Enfermagem da Faculdade de Medicina de São José do Rio Preto - Mestranda do Curso de Pós-Graduação em Enfermagem da Escola de Enfermagem de Ribeirão Preto da Universidade de São Paulo

** Professor Titular do Departamento de Enfermagem Geral e Especializada da Escola de Enfermagem de Ribeirão Preto da Universidade de São Paulo. Orientadora do Estudo
} 
administradora de empresa, assessorada por duas médicas) e pela Diretoria Clínica (cargo ocupado por uma médica).

Refletindo sobre as relações entre esses níveis hierárquicos, percebia que, à semelhança do que ocorria em outras instituições de saúde, o cotidiano do gerente de enfermagem baseava-se no estabelecimento de normas e rotinas das ações de enfermagem.

$\mathrm{Na}$ revisão da literatura acerca das diferentes temáticas que envolvem o gerenciamento das instituições de saúde hospitalares, busquei subsídios que me possibilitassem a análise do estilo gerencial do diretor executivo no hospital em estudo, na concepção da gerência e assessoria do serviço de enfermagem, no aspecto idealizado para esse profissional.

A administração tem sofrido mudanças ao longo do tempo e para avançar, deve adequar-se às novas tendências mundiais, inserindo novos conceitos e novas modalidades de gestão, visando melhor rendimento e aproveitamento nas organizações (TAPPAN, 1976; GARAPINHEIRO, 1993; RODRIGUES FILHO, 1994).

KERTESZ (1984) enfatiza que a grande dificuldade no gerenciamento do serviço de enfermagem é a relação dos gerentes enfermeiros com a administração do hospital, que muitas vezes relegam a plano secundário os interesses e as necessidades deste serviço.

MOTTA (1991) entende que a gerência de enfermagem não tem grande poder de interferência no hospital, configurando-se mais numa função de "governanta" da organização, com poderes limitados.

Para traduzir as expectativas dos enfermeiros deste estudo quanto ao estilo gerencial do diretor executivo da instituição estudada utilizou-se como referencial o Grid Gerencial de BLAKE \& MOUTON (1987), que busca elucidar as premissas que os gerentes utilizam ao competirem ou cooperarem uns com os outros, cuja análise apresenta duas dimensões: orientação para produção (resultados) e orientação para as pessoas (relacionamento).

Essas duas orientações podem ser observadas na Figura 1 por 2 escalas de nove pontos. O número 1 representa orientação mínima, o número 5 orientação média e o número 9 , orientação máxima.

O interesse pela produção está ilustrado no eixo horizontal e o interesse pelas pessoas, no eixo vertical. Em cada eixo encontramos uma escala de 9 pontos que indica o grau de interesse em cada dimensão. Dessa forma, há 81 combinações possíveis entre orientação para produção e pessoas, porém a Teoria Grid determina a identidade de 5 estilos essenciais: 9.1; 1.9; 1.1; 5.5 e 9.9 .

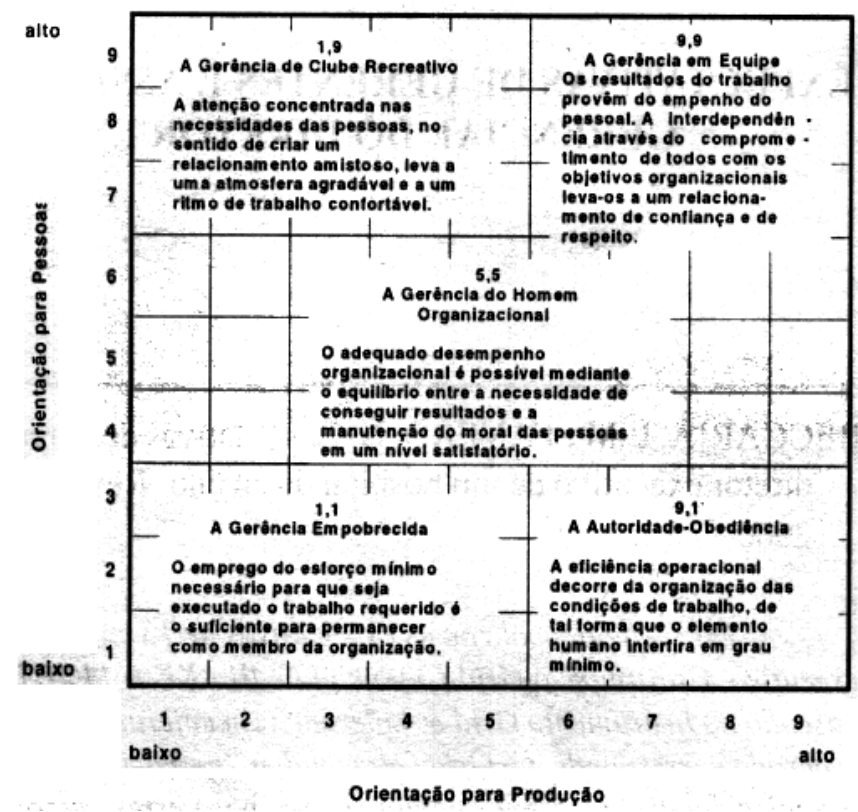

Fonte: BLAKE, R.R.; MOUTON, J.S. O novo grid gerencial. (The new manegerial grid) 4. ed. São Paulo: Pioneira, 1987. p. 13.

\section{Figura 1- O grid gerencial}

A orientação do estilo 9.1 é máxima para a produção e mínima para as pessoas. $\mathrm{O}$ administrador preocupa-se em obter o máximo de produção com um mínimo de interferência das pessoas. Assim, a conduta do gerente deste estilo baseia-se na hierarquia e no poder coercitivo, pois é estimulada pela necessidade de poder, controle e domínio sobre as pessoas e por medo de fracassar e de não dominar a situação. Sua meta é vencer, dominar e se fracassa atribui a culpa aos outros. Orientase pelas máximas: "Nunca confie nos outros" e "não aceite conselhos e orientações".

O estilo 1.9 reúne a orientação mínima para a produção e a orientação máxima para as pessoas. A ênfase dada aqui se relaciona ao estabelecimento de sentimentos positivos entre colegas e subordinados. O gerente deste estilo busca a aprovação de todos, dando importância a um relacionamento amistoso, estando atento aos sentimentos e necessidades dos subordinados como forma de sentir a compreensão, o afeto e o apoio dos que lhe rodeiam, mostrando-se atencioso, gentil, bondoso e prestativo.

A posição 1.1 associa a orientação mínima tanto para a produção como para as pessoas, e neste sentido, o gerente que adota este estilo se preocupa em realizar apenas o mínimo necessário para se manter na organização. Este tipo de gerente mostra-se indiferente e atua apenas o suficiente para preservar seu emprego, isto é, espera pouco e oferece pouco. Seu lema é: "não veja nada de errado, não diga nada de errado, não ouça nada 
de errado e você estará protegido, pois nem será notado". No estilo 5.5, há uma combinação de orientação mediana para a produção e para as pessoas. O administrador busca um desempenho satisfatório da organização através de um equilíbrio entre as metas da produção e a conservação do moral das pessoas. Acrescenta TREVIZAN (1993) que a motivação positiva da gerência do homem organizacional, ou 5.5 é participar, causar boa impressão, obter aceitação de seu grupo, ser associável, angariar um extenso círculo de relacionamentos, demonstrar "status". Por outro lado o seu grande receio é não ser aceito pelo grupo, sentir-se impopular e isolado.

Na posição 9.9 existe uma orientação máxima para produção (bons resultados) com orientação máxima para as pessoas (bom relacionamento). É caracterizado pela gerência em equipe, pois o desafio da gerência moderna é estabelecer metas mais altas do que as consideradas no Estilo 5.5 e alcançá-las por meio da participação, envolvimento e comprometimento. Este tipo de gerente fundamenta-se nas necessidades organizacionais de produção e nas necessidades que as pessoas têm de experiências plenas e compensadoras no trabalho. Busca a participação ativa e a integração das pessoas através de abertura, espontaneidade e responsabilidade compartilhada na consecução de metas claras e desafiadoras.

\section{OBJETIVO}

Conhecer as expectativas de gerentes e assessores do serviço de enfermagem quanto ao estilo gerencial do diretor executivo da Instituição.

\section{METODOLOGIA}

O projeto de pesquisa foi encaminhado ao Comitê de Ética em Pesquisa da Instituição para análise e emissão de parecer.

Trata-se de uma pesquisa descritiva realizada em um hospital escola, de grande porte, campo de prática de estudantes de graduação em medicina e enfermagem, localizado no interior do Estado de São Paulo.

Participaram deste estudo 13 enfermeiros gerentes e assessores do serviço de enfermagem, que desenvolveram essas funções nos últimos 10 anos.

Para a coleta dos dados utilizou-se um questionário estruturado segundo o modelo proposto por TREVIZAN (1993), no enfoque do estilo Grid (Anexo).

\section{RESULTADOS E DISCUSSÃO}

Para a análise dos dados foi atribuído um valor específico à cada uma das quatro alternativas de respostas para as vinte e cinco proposições do instrumento. A análise individual dos valores atribuídos viabilizou a percepção da expectativa dos enfermeiros quanto ao estilo gerencial do diretor executivo, conforme pode-se observar na Figura 2.

\begin{tabular}{|c|c|c|c|c|c|}
\hline Sujeitos & $\begin{array}{c}\text { Expectativa } \\
1.1\end{array}$ & $\begin{array}{c}\text { Expectativa } \\
19\end{array}$ & $\begin{array}{c}\text { Expectativa } \\
55\end{array}$ & $\begin{array}{c}\text { Expectativa } \\
9.1\end{array}$ & $\begin{array}{c}\text { Expectativa } \\
99\end{array}$ \\
\hline 1 & 11 & 10 & 14 & 5 & 17 \\
\hline 2 & 9 & 12 & 16 & 8 & 18 \\
\hline 3 & 14 & 17 & 18 & 10 & 20 \\
\hline 4 & 11 & 11 & 17 & 7 & 20 \\
\hline 5 & 12 & 18 & 17 & 6 & 18 \\
\hline 6 & 12 & 16 & 15 & 9 & 17 \\
\hline 7 & 12 & 19 & 16 & 10 & 17 \\
\hline 8 & 5 & 16 & 19 & 8 & 20 \\
\hline 9 & 12 & 15 & 18 & 6 & 18 \\
\hline 10 & 10 & 14 & 18 & 5 & 18 \\
\hline 11 & 9 & 16 & 18 & 9 & 17 \\
\hline 12 & 14 & 18 & 19 & 10 & 18 \\
\hline 13 & 10 & 15 & 17 & 9 & 18 \\
\hline Total & 141 & 197 & 222 & 102 & 236 \\
\hline Média & 10,8 & 15,1 & 17 & 7,8 & 18,1 \\
\hline
\end{tabular}

Figura 2 - Distribuição dos valores atribuídos pelos enfermeiros ao estilo gerencial idealizado para o diretor executivo 
Incluiu-se a somatória individual dos valores atribuídos pelos enfermeiros em quatro categorias, da forma como segue:
Valor 5

Valor de 06 a 12

Valores de 13 a 19

Valor 20
Totalmente desejável

Indesejável

Desejável

Totalmente desejável

Tabela 1 - Demonstrativo do comportamento gerencial do diretor executivo idealizado pelos enfermeiros do estudo, segundo estilo Grid

\begin{tabular}{|c|c|c|c|c|c|c|c|c|}
\hline \multirow{3}{*}{ Estilo } & \multicolumn{8}{|c|}{ Comportamento } \\
\hline & \multicolumn{2}{|c|}{ To talmente des ejável } & \multicolumn{2}{|c|}{ Desejável } & \multicolumn{2}{|c|}{ Indesejável } & \multicolumn{2}{|c|}{ Totalmente indesejável } \\
\hline & $\mathrm{N}^{\mathrm{a}}$ & $\%$ & $\mathrm{~N}^{\mathrm{a}}$ & $\%$ & $\mathrm{~N}^{\mathrm{o}}$ & $\%$ & $\mathrm{~N}^{0}$ & $\%$ \\
\hline 9.9 & 03 & 23 & 10 & 77 & - & - & - & - \\
\hline 5.5 & - & - & 13 & 100 & - & - & - & - \\
\hline 1.9 & & & 10 & 77 & 3 & 23 & - & - \\
\hline 1.1 & - & - & 2 & 15,3 & 10 & 77 & 1 & 7,7 \\
\hline 9.1 & - & - & - & - & 11 & 84,7 & 2 & 15,3 \\
\hline
\end{tabular}

Chama atenção na análise da Tabela 1 que os enfermeiros do estudo têm expectativa de que o diretor executivo, tenha o estilo gerencial 9.9, considerado totalmente desejável para $23 \%$ e desejável para $77 \%$. Assim, esperam que ele seja aberto, participativo, incentivador e compromissado com todo o grupo.

No que tange aos outros estilos gerenciais, ficou em evidência que o estilo 5.5 foi citado como desejável para $100 \%$ dos enfermeiros; o estilo 1.9 foi referido como desejável para $77 \%$ e o estilo 1.1 foi considerado como desejável para $15,3 \%$ e indesejável para $77 \%$.

Também, a maioria deles $(84,7 \%)$ considera o estilo 9.1 como indesejável e, portanto, não desejam um diretor executivo exigindo um trabalho voltado apenas para a execução de tarefas atribuídas, sem consideração com os subordinados.

Na Figura 3, encontra-se o diagrama esquemático onde estão registradas as informações sobre os valores acumulados acerca das expectativas dos enfermeiros para os estilos de gerência idealizados para o diretor executivo.

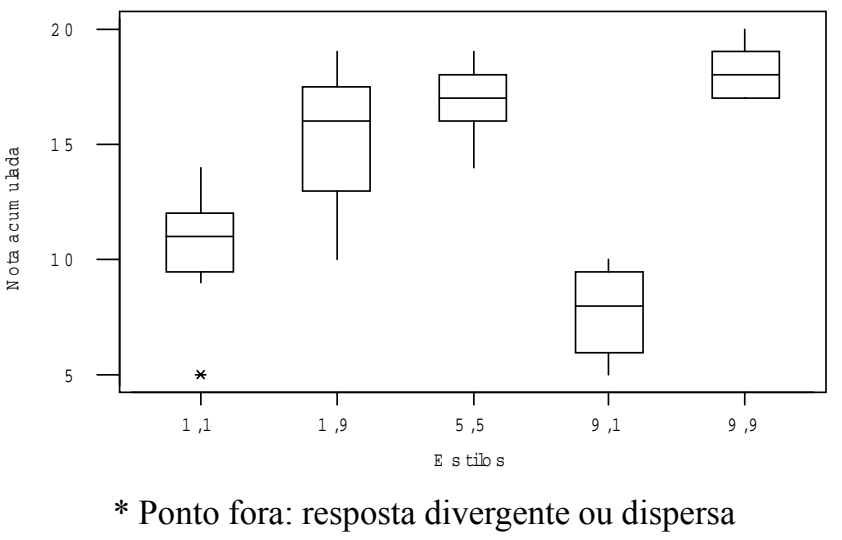

Figura 3 - Convergência e dispersão de respostas em relação às expectativas dos enfermeiros quanto ao estilo de gerência do diretor executivo
Analisando-se as convergências de expectativas e a dispersão nas respostas individuais nota-se que houve maior dispersão nas respostas individuais acerca do estilo 1.9. Também demostra que o 9.1 é o estilo menos desejado e o 9.9, o mais desejado, apresentando-se de forma mais homogênea em relação aos demais, o que significa menor dispersão.

Por outro lado, evidencia-se um ponto fora, que significa um valor dentre as 65 combinações possíveis para este estilo, ter sido muito baixa em relação às demais.

Quanto à expectativa ficou evidenciado, por parte dos enfermeiros que o diretor executivo apresente preferencialmente o estilo gerencial 9.9, como desejável.

Isto significa que eles almejam um diretor que tenha um estilo gerencial altamente orientado tanto para resultados como para as necessidades do grupo. Um diretor que promova a integração entre o serviço de enfermagem e os demais profissionais; que incentive a participação e o compromisso de todos na busca de melhor qualidade do serviço; que propicie um clima de abertura, franqueza e confiança, buscando solucionar os conflitos através da exposição aberta dos fatos; que solucione as causas dos problemas juntamente com as pessoas envolvidas; que procure estar sempre atualizado na sua área, incentivando também os liderados para atualização.

Para TREVIZAN (1993, p. 64),“a eficácia da liderança depende da utilização de um estilo comportamental conveniente aos quesitos do ambiente, por parte do líder, em conseqüência, é indispensável que ele diagnostique seu ambiente de atuação".

TANNENBAUM \& SCHMIDT (1977) relatam que um líder bem sucedido é aquele que está consciente das forças relevantes que afetam seu comportamento, compreendendo a si próprio e aos subordinados, desenvolvendo-os no ambiente social no qual opere. 
Ainda, percebe-se que em relação ao comportamento ideal do diretor executivo, os enfermeiros optaram em segundo lugar pelo estilo 5.5. Isto significa que os enfermeiros almejam, que o mesmo, busque soluções conciliatórias na resolução de conflitos, se apoie na opinião da maioria, que leve em consideração as sugestões e opiniões dos subordinados, que encoraje e incentive o grupo, que reduza a pressão como forma de garantir um serviço de qualidade.

Segundo TREVIZAN (1993), o gerente 5.5 procura manter uma posição satisfatória entre as exigências do serviço e das pessoas, colocando-se apenas um ponto acima dos subordinados, acreditando estar assim bem posicionado como chefe.

De uma forma geral, o que ficou em evidência pelos resultados deste estudo é que os enfermeiros esperam que o diretor executivo relacione-se com os subordinados de forma a manter um vínculo inseparável entre as necessidades de produção e as das pessoas, com participação ativa de todos, envolvimento e comprometimento com padrões de excelência e com forte espírito de trabalho em equipe.

Também idealizam os enfermeiros desta pesquisa, que, no desempenho do trabalho do diretor executivo, haja planejamento das atividades, com envolvimento das pessoas, onde sejam compartilhadas as perspectivas e ações, consideradas as idéias dos profissionais, estabelecidos programas flexíveis. Enfim, que a organização do trabalho seja realizada junto com os subordinados, determinando-se as responsabilidades individuais.

Confrontando os dados do presente estudo com os resultados encontrados por TREVIZAN ( 1993) podese observar que, em relação ao comportamento idealizado para o líder, houve uma concordância subseqüente pelos estilos 9.9, 5.5 e 1.9 do Grid Gerencial de Blake e Mouton.

CAMPOS (1990) entende que o trabalho de modo cooperativo não implica em trabalho sem conflitos, eles existem sempre e devem ser encarados como um elemento que propicia mudanças. A presença deles é inevitável e universal.

Neste estudo o perfil do diretor executivo, na opinião dos enfermeiros, deveria ser o de uma pessoa comprometida, aberta, espontânea, flexível e participante, visto que tal comportamento gera uma reação para a maioria dos subordinados de entusiasmo e de satisfação.

QUICK (1995) enfatiza que equipes bem sucedidas são aquelas que compartilham com seus membros as informações oportunas sobre o que ocorre com toda a organização.

Nas últimas décadas as organizações estão se encaminhando lentamente em direção ao estilo 9.9, pois é o que leva à obtenção de maior lucratividade (BLAKE $\&$ MOUTON, 1987).
VASCONCELOS \& HEMSLEY (1997) relatam que com o aumento da complexidade das organizações, tornou-se necessário a existência de formas inovativas de administração, que possam responder de maneira eficaz a essas mudanças, onde as características estruturais sejam inversas àquelas apresentadas pelas organizações tradicionais, ou seja, com baixo nível de formalização, multiplicidade de comando, diversificação elevada, comunicação horizontal e diagonal.

Neste enfoque, SANTANA (1993) relata que os gerentes dos serviços de saúde devem discutir e implementar medidas que considerem a importância dos profissionais na vida das organizações, utilizando-se de uma prática administrativa de forma participativa, propiciando abertura de espaços para a criatividade e iniciativa dos trabalhadores, substituindo o controle pela responsabilização para com os objetivos e práticas institucionais.

Quanto ao estilo 1.1, classificado em quarto lugar, foi apontado como desejável para $15,4 \%$ dos enfermeiros. Ao comparar este dado com os resultados dos trabalhos de GALVÃO (1990) e TREVIZAN (1993), pode-se verificar discordância nesse sentido, pois o estilo 1.1 foi classificado em último lugar, sendo considerado um comportamento indesejável nos trabalhos das autoras citadas.

O estilo de gerência 9.1, voltado exclusivamente para a produção foi considerado em último lugar de preferência, estando, para a maioria, relacionado ao estilo indesejável e, para os restantes, associado ao estilo totalmente indesejável.

\section{CONCLUSÕES}

Este estudo foi desenvolvido com o objetivo de conhecer as expectativas de 13 gerentes e assessores do serviço de enfermagem de um Hospital de Ensino quanto ao estilo gerencial do diretor executivo da Instituição. Por meio da análise dos dados concluiu-se que a expectativa maior destes enfermeiros está relacionada ao estilo 9.9 do Grid gerencial (Blake \& Mouton, 1987, p.13) seguida pelo estilo 5.5. Ao estilo 9.9 está associado o desejo de um comportamento gerencial voltado para o trabalho em equipe, com comprometimento e envolvimento interpessoal. Ao estilo 5.5 está associado o desejo de uma organização com desempenho satisfatório obtido por meio do equilíbrio entre as metas relacionadas à produção e à preservação do moral dos trabalhadores. 
THE MANAGERIAL STYLE OF AN EXECUTIVE DIRECTOR OF A UNIVERSITY HOSPITAL: PERCEPTIONS AND EXPECTATIONS OF NURSING MANAGERS AND ASSISTANTS

The present study focussed the expectations of 13 nurses from a University hospital regarding to the executive director's managerial style. The Managerial Grid of BLAKE \& MOUTON (1987) was used as a theoretical reference and a questionnaire was applied based on the Grid \& Leadership in Nursing Instrument elaborated by TREVIZAN (1993). Results evidenced that the most expected style corresponds, considering the Managerial Grid, to "team management", or 9.9. The second style was the "management of a men organization", or 5.5. Authors concluded that there are important expectations for these nurses related to a management that enhances values such as trust, respect, commitment, personal investment and team work in order to achieve the organization goals.

\section{EXPECTATIVAS DE GERENTES Y ASESORES DE ENFERMERIA REFERENTE AL ESTILO GERENCIAL DEL DIRECTOR EJECUTIVO DE UN HOSPITAL ESCUELA}

Este estudio enfocó las expectativas de 13 enfermeros del hospital escuela, con relación al estilo directivo del director ejecutivo. El "grid" gerencial de BLAKE \& MOUTON (1987), fue usado como referencial teórico y una encuesta se aplicó basada en el Instrumento Grid \& Liderazgo en enfermería, de TREVIZAN (1993). Los resultados evidenciaron el estilo más esperado fue "la gerencia en equipo", o 9.9. EL segundo estilo fue la "gerencia organizacional del hombre," o 5.5. Se concluye que, para esos enfermeros existen expectativas significativas relacionadas con la dirección que invierte en valores como confianza, respeto, compromiso, empeño personal y trabajo en equipo para el alcance del objetivos organizacionales.

TÉRMINOS CLAVES: gerencia, liderazgo, enfermería

\section{ANEXO}

\section{I - DADOS DE IDENTIFICAÇÃO:}

- Idade

- Ano de conclusão da graduação

- Especialização

- Tempo de atuação na instituição

\section{II - PROPOSIÇÕES}

- Tempo de atuação no serviço de enfermagem do Hospital de Base

- como gerente: como assessor:

- Experiência em gerência em outra instituição

- Como você chegou à gerência ou à assessoria do serviço de enfermagem desta instituição?

- Qual o motivo que o levou a deixar o cargo de gerente ou de assessor do serviço de enfermagem nesta instituição

\begin{tabular}{|c|c|c|c|c|}
\hline Proposições & $\begin{array}{l}\text { Totalmente } \\
\text { desejável }\end{array}$ & Desejável & Indesejável & $\begin{array}{l}\text { Totalmente } \\
\text { indesejável }\end{array}$ \\
\hline $\begin{array}{l}\text { 1- O diretor executivo deveria estar sempre atento à opinião do gerente do } \\
\text { serviço de enfermagem, mantendo uma posição intermediária entre as } \\
\text { exigências da instituição e as exigências do serviço de enfermagem. }\end{array}$ & & & & \\
\hline $\begin{array}{l}\text { 2- O diretor executivo deveria demonstrar pouca preocupação tanto com o } \\
\text { serviço de enfermagem, quanto com as pessoas e esforçar-se apenas o } \\
\text { suficiente para preservar sua função (cargo). }\end{array}$ & & & & \\
\hline $\begin{array}{l}\text { 3- Se ocorresse conflito ou tensão no serviço de enfermagem, o diretor } \\
\text { executivo deveria procurar conhecer os motivos, através da exposição aberta } \\
\text { dos fatos, para juntamente com o gerente do serviço de enfermagem, } \\
\text { solucionar as causas do problema. }\end{array}$ & & & & \\
\hline $\begin{array}{l}\text { 4- O diretor executivo deveria fazer todo o possível para que o gerente do } \\
\text { serviço de enfermagem se sentisse satisfeito com as condições de trabalho. }\end{array}$ & & & & \\
\hline
\end{tabular}




\begin{tabular}{|c|c|c|c|c|}
\hline Proposições & $\begin{array}{c}\text { Totalmente } \\
\text { desejável }\end{array}$ & Desejável & Indesejável & $\begin{array}{l}\text { Totalmente } \\
\text { indesejável }\end{array}$ \\
\hline $\begin{array}{l}\text { 5- Para evitar o conflito, o diretor executivo deveria seguir as normas e as } \\
\text { rotinas do hospital ou se apoiar na opinião da maioria; quando ocorresse o } \\
\text { conflito, o diretor executivo deveria buscar soluções conciliatórias para a } \\
\text { situação. }\end{array}$ & & & & \\
\hline $\begin{array}{l}\text { 6- A atuação do diretor executivo deveria propiciar um clima de abertura, } \\
\text { franqueza e confiança. }\end{array}$ & & & & \\
\hline $\begin{array}{l}\text { 7- Para o diretor executivo os resultados é que deveriam contar. Assim, } \\
\text { teria mais interesse pelos serviços e demonstraria menor consideração com } \\
\text { o gerente do serviço de enfermagem, pressionando-o e controlando-o para } \\
\text { que fosse eficiente. }\end{array}$ & & & & \\
\hline $\begin{array}{l}\text { 8- O relacionamento entre o diretor executivo e a gerência do serviço de } \\
\text { enfermagem deveria se fazer através da relação de mando e obediência. }\end{array}$ & & & & \\
\hline $\begin{array}{l}\text { 9- O padrão de comportamento do diretor executivo deveria ser } \\
\text { extremamente democrático de forma a deixar o gerente do serviço de } \\
\text { enfermagem bem à vontade no trabalho. }\end{array}$ & & & & \\
\hline $\begin{array}{l}\text { 10- O diretor executivo deveria dirigir seus esforços visando unicamente } \\
\text { atender aos objetivos do hospital. }\end{array}$ & & & & \\
\hline $\begin{array}{l}\text { 11- Ao planejar e organizar o trabalho, o diretor executivo deveria levar } \\
\text { em consideração as sugestões do gerente do serviço de enfermagem. }\end{array}$ & & & & \\
\hline $\begin{array}{l}\text { 12- O diretor executivo deveria transmitir ordens emanadas do conselho } \\
\text { de curadores com a máxima fidelidade, sem emitir sua opinião sobre as } \\
\text { mesmas; o seu papel na transmissão dessas ordens deveria ser de mero } \\
\text { "porta-voz". }\end{array}$ & & & & \\
\hline $\begin{array}{l}\text { 13- O diretor executivo deveria procurar estar sempre atualizado na sua } \\
\text { área e incentivar também a gerência do serviço de enfermagem para } \\
\text { atualização. }\end{array}$ & & & & \\
\hline $\begin{array}{l}\text { 14- O diretor executivo deveria dar menor importância aos objetivos do } \\
\text { hospital e atribuir maior importância às necessidades, atitudes e aos } \\
\text { sentimentos do gerente de enfermagem. }\end{array}$ & & & & \\
\hline $\begin{array}{l}\text { 15- Se ocorressem situações de conflito ou problemas relativos ao serviço } \\
\text { de enfermagem, o diretor executivo deveria manter-se neutro, isto é, não } \\
\text { se envolver. }\end{array}$ & & & & \\
\hline $\begin{array}{l}\text { 16- O diretor executivo deveria promover periodicamente encontros } \\
\text { informais com o gerente de enfermagem para analisar o andamento do } \\
\text { serviço, ressaltando os pontos positivos, de modo a encorajar a superação } \\
\text { dos pontos fracos, reduzindo a pressão sempre que possível. }\end{array}$ & & & & \\
\hline $\begin{array}{l}\text { 17- O comportamento do diretor executivo deveria ser participante e } \\
\text { voltado para os interesses do grupo. }\end{array}$ & & & & \\
\hline $\begin{array}{l}\text { 18- O diretor executivo deveria se empenhar, sobretudo, em cultivar uma } \\
\text { atmosfera de calor humano no ambiente de trabalho. }\end{array}$ & & & & \\
\hline $\begin{array}{l}\text { 19- O diretor executivo deveria evitar interferir nas tarefas do gerente do } \\
\text { serviço de enfermagem, já que não está diretamente envolvido com o } \\
\text { trabalho. }\end{array}$ & & & & \\
\hline
\end{tabular}




\begin{tabular}{|c|c|c|c|c|}
\hline Proposições & $\begin{array}{c}\text { Totalmente } \\
\text { desejável }\end{array}$ & Desejável & Indesejável & $\begin{array}{l}\text { Totalmente } \\
\text { indesejável }\end{array}$ \\
\hline $\begin{array}{l}\text { 20- O diretor executivo deveria atribuir responsabilidade ao serviço de } \\
\text { enfermagem através de tarefas determinadas, dizendo ao gerente do } \\
\text { serviço de enfermagem: o que fazer, como fazer, quando fazer, onde fazer } \\
\text { e com quem fazer, além de dar maior importância ao desempenho } \\
\text { individual em detrimento do trabalho em grupo. }\end{array}$ & & & & \\
\hline $\begin{array}{l}\text { 21- O diretor executivo deveria procurar alcançar integração entre o } \\
\text { serviço de enfermagem e os demais profissionais. Para isso deveria } \\
\text { incentivar a participação e o compromisso de todos na busca de melhor } \\
\text { qualidade no atendimento ao usuário. }\end{array}$ & & & & \\
\hline $\begin{array}{l}\text { 22- As avaliações de desempenho do gerente do serviço de enfermagem } \\
\text { deveriam ser executadas de maneira superficial pelo diretor executivo. }\end{array}$ & & & & \\
\hline $\begin{array}{l}\text { 23- Quando houvesse conflito o diretor executivo deveria usar sua } \\
\text { autoridade para resolvê-lo, fazendo prevalecer sua decisão. }\end{array}$ & & & & \\
\hline $\begin{array}{l}\text { 24- O diretor executivo deveria manter as portas sempre abertas para o } \\
\text { gerente do serviço de enfermagem; procurar atender a todas as suas } \\
\text { solicitações e congratular-se com ele pelo andamento dos trabalhos, } \\
\text { evitando críticas que possam constrangê-lo. }\end{array}$ & & & & \\
\hline $\begin{array}{l}\text { 25- O diretor executivo deveria preocupar-se em garantir uma assistência } \\
\text { de qualidade na instituição, sem incomodar o gerente do serviço de } \\
\text { enfermagem. }\end{array}$ & & & & \\
\hline
\end{tabular}

\section{REFERÊNCIAS BIBLIOGRÁFICAS}

01. BLAKE, R.R.; MOUTON, J.S. O novo grid gerencial. (The new manegerial grid). 4.ed. São Paulo: Pioneira, 1987. 315p.

02. CAMPOS, M.A. O trabalho em equipe multiprofissional: uma reflexão crítica. 1990. 10p. /mimeografado/

03. GALVÃO, C.M. Liderança do enfermeiro de centro cirúrgico. Ribeirão Preto, 1990. 69p. Dissertação (Mestrado) - Escola de Enfermagem de Ribeirão Preto, Universidade de São Paulo.

04. GARAPINHEIRO, G. Saberes e poderes no hospital: uma sociologia dos serviços hospitalares. Lisboa: Edições Afrontamento, 1993. 295p.

05. KERTESZ, P.M. Gerenciamento no serviço de enfermagem. O mundo da saúde. São Paulo, n. 4, p. 160-3, out/nov/dez. 1984.

06. MOTTA, P.R. Gestão contemporânea: a ciência e a arte de ser dirigente. 2. ed. Rio de Janeiro: Record, 1991. 256p.
07. QUICK, T.L. Como desenvolver equipes bem sucedidas. Rio de Janeiro: Campus, 1995. 118p.

08. RODRIGUES FILHO, J. A crise gerencial no sistema de saúde. Rev. Adm. Publica, Rio de Janeiro, v. 28, n. 4, p. 65-75, out/dez. 1994.

09. SANTANA, L.P. A gestão do trabalho nos estabelecimentos de saúde: elementos para uma proposta. Cad. R H Saúde, Brasília, v. 1, n. 3. p 51-62, nov. 1993.

10. TANNENBAUM, R.; SCHMIDT, W.H. Como escolher um padrão de liderança. In: BALCÃO, Y.F.; CORDEIRO, L.L. O comportamento humano na empresa: uma antologia. 3.ed. Rio de Janeiro: Fund. Getúlio Vargas, 1977.

11. TAPPAN, F.M. Administração hospitalar. (Administration hospital). São Paulo: EDART, 1976. 174p.

12. TREVIZAN, M.A. Liderança do enfermeiro: o ideal e o real no contexto hospitalar. São Paulo: Sarvier, 1993. 94p.

13. VASCONCELOS, E.; HEMSLEY, J.R. Estrutura das organizações. 3. ed. São Paulo: Pioneira, 1997. 208p. 